\title{
Pesquisa-ação: \\ proposição metodológica para o planejamento das ações nos serviços de atenção primária no contexto da saúde ambiental e da saúde do trabalhador
}

\author{
Vanira Matos Pessoa \\ Raquel Maria Rigotto² \\ Carlos André Moura Arruda ${ }^{3}$ \\ Maria de Fátima Antero Sousa Machado ${ }^{4}$ \\ Márcia Maria Tavares Machado ${ }^{5}$ \\ Maria das Graças Viana Bezerra ${ }^{6}$
}

PESSOA, V. M. et al. Action research:methodological proposal for action planning in primary care services in the context of environmental health and occupational health. Interface (Botucatu), v.17, n.45, p.301-14, abr./jun. 2013.

The Brazilian health system proposes actions to operationalize environmental health and worker, in order to address the complexity of the disease process in the territories. The objective is to present the action research as a methodological approach, facilitating the analysis of complex webs of economic development and the implications on labor, environment and health in communities in Brazilian Northeast. Action research is designed with a group of 14 subjects and was conducted in the form of workshops. In making the research and development of linkages flowed propositions from the theory-reflectionaction subjects. The method has a potential to denude complex problems related to environmental health and worker, it favors human interaction built the place in which he lives.

Keywords: Action research. Environmental health. Occupational health. Primary health care.
O Sistema Único de Saúde no Brasil propõe a operacionalização de ações de saúde ambiental e do trabalhador, com vistas a abordar a complexidade do processo saúde-doença nos territórios. Objetiva-se apresentar a pesquisa-ação como um percurso metodológico, facilitador da análise das complexas tramas do desenvolvimento econômico e as implicações no trabalho, ambiente e saúde, em comunidades do Nordeste brasileiro. A pesquisa-ação foi concebida com um grupo de 14 sujeitos e foi conduzida no formato de oficinas. $\mathrm{Na}$ feitura da pesquisa fluíram vínculos e elaboração de proposições, a partir da reflexão-teorização-ação dos sujeitos. Destaca-se que o método apresenta um potencial para desnudar problemas complexos relacionados à saúde ambiental e do trabalhador, pois favorece a interação humana integrada ao lugar em que vive.

Palavras-chave: Pesquisa-ação. Saúde ambiental. Saúde do trabalhador. Atenção primária à saúde.

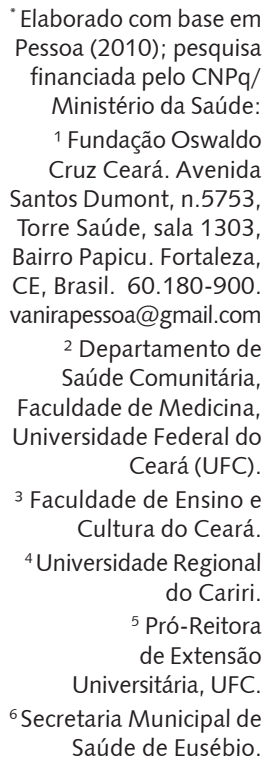

“Elaborado com base em 2010); pesquis

valdo Santos Dumont, n.5753, Torre Saúde, sala 1303 ( anirapessoa@gmail.com

2 Departamento de Saúde Comunitária Universidade Federal do Ceará (UFC)

Faculdade de Ensino e Regional do Cariri. de Extensão Universitaria, UFC. Saúde de Eusébio. 


\section{Introdução}

As transformações nos territórios locais decorrentes dos processos produtivos ensejam mudanças no modo de viver das comunidades, sobretudo dos trabalhadores. Alguns estudos, dentre eles, o de Rigotto e Augusto (2007), destacam que já são reconhecidas as relações sistêmicas entre as políticas econômicas em curso e os efeitos socioambientais observados, como o aumento expressivo da morbimortalidade por causas externas decorrentes da violência, dos processos produtivos e da pressão promovida para adoção de novos padrões de consumo.

A reestruturação produtiva precisa ser compreendida pelos trabalhadores, moradores e profissionais de saúde nos territórios, tendo em vista que este enfoque possibilita a delimitação e caracterização da população e de seus problemas de saúde na Atenção Primária à Saúde (APS), com vistas ao desenvolvimento de ações e o fortalecimento do acesso a estes serviços (Dias et al., 2009). Dessa forma, torna-se essencial a compreensão sistêmica dos processos que reorganizam os territórios e a vida das pessoas sob a responsabilidade sanitária da APS, nos moldes da Estratégia Saúde da Família (ESF). Cabe, atualmente, à ESF efetivar os princípios do Sistema Único de Saúde (SUS), por meio da coordenação do cuidado na rede de serviços, constituindo relações de vínculos e responsabilização com a população do território, promovendo a integração das ações programáticas e demanda espontânea, articuladas às ações de promoção à saúde, prevenção de agravos, vigilância à saúde, tratamento e reabilitação (Brasil, 2011).

Além disso, a ESF deve estimular a participação popular e o controle social, pois se acredita que a articulação das ações de forma transdisciplinar e intersetorial pode garantir o acesso e a organização dos serviços de saúde, a continuidade das ações e a longitudinalidade do cuidado aos moradores do território local. Nessa perspectiva, o reconhecimento das necessidades de saúde e o planejamento de ações para o território local são fundamentais na ESF (Brasil, 2006).

O reconhecimento dos processos produtivos está em consonância com as ações da ESF e contribui para o desenvolvimento da atuação crítica e autônoma dos profissionais de saúde no território, com base nas necessidades de saúde locais, visando à melhoria da qualidade de vida, potencializando a cidadania e a sustentabilidade.

Para tal, é imprescindível o entendimento dos pressupostos da saúde ambiental e do trabalhador na APS, que estão embasados na compreensão apontada por Santos e Câmara (2002) de que, no ambiente, os processos produtivos de desenvolvimento social e econômico interferem nas relações que se desenvolvem nos ecossistemas. Isto porque determinam e contribuem para a existência de condições ou situações de risco, que influenciam o padrão de saúde das populações que sofrem alterações no seu perfil de morbimortalidade, a partir de diferentes fontes e modalidades de poluição (acumulação dos elementos abióticos causadores de agravos), de contaminação (presença de agentes biológicos de doenças), e das formas de constituição de dinâmicas ambientais que possibilitem a liberação descontrolada de formas específicas de energia.

A conjuntura em que se insere o sistema de saúde brasileiro está submetida à política econômica numa perspectiva desenvolvimentista, que fortalece a implantação de novos empreendimentos, a exemplo do Programa de Aceleração do Crescimento (PAC). Isto requer do SUS estar atento às novas necessidades de saúde para garantir o acesso e atuar com resolubilidade diante das expectativas da população brasileira. Estes empreendimentos estão centrados na lógica do crescimento econômico como substrato para promover mudanças sociais apostando na geração de emprego e renda, sem, contudo, estarem articulados à implantação de políticas públicas que respondam às novas necessidades que são produzidas.

Nesse contexto, o Nordeste brasileiro é a macrorregião com maior proporção de pessoas pobres do País. Ou seja, o percentual da população com renda familiar per capita de até meio salário-mínimo corresponde a $52 \%$, apresentando uma diferença de dez pontos percentuais da região norte, que é a segunda colocada, enquanto a média nacional é de 31\%. Em relação ao estado do Ceará, local onde realizamos este estudo, a proporção de pobres é de $51 \%$, evidenciando a situação de desigualdade social, iniquidade social e de saúde visível na América Latina (Brasil, 2012). 
Assim, para se minimizarem tais desigualdades, tem sido intensificado o investimento estatal, tanto por meio de subsídios e capital político, na intencionalidade de ser um polo de atração da indústria e se inserir no contexto nacional e internacional capitalista. A perspectiva da geração de emprego e renda constitui uma estratégia para realçar o desenvolvimento econômico do Estado, onde se destaca o agronegócio, o incentivo ao turismo e a industrialização (Ceará, 2012).

Defendemos que as demandas e os impactos à saúde decorrentes deste processo desenvolvimentista não estão explicitados e não são avaliados sistematicamente no âmbito do SUS, sobretudo da APS, para que haja adaptações e iniciativas, visando a capacidade de prover e garantir, aos cidadãos, respostas efetivas às necessidades de saúde vinculadas à relação capital-trabalho.

Do exposto, acreditamos que a pesquisa-ação na APS, no contexto da saúde ambiental e do trabalhador, apresenta-se como uma estratégia capaz de elaborar novos instrumentos metodológicos com sensibilidade para captar as informações acerca dos processos produtivos e as implicações à saúde e ao ambiente. E, ainda, propiciar o reconhecimento das necessidades de saúde, garantindo o acesso dos usuários aos serviços por meio de ações planejadas pela equipe de saúde da família no território, com vistas à tomada de decisão.

Nestas perspectivas, este manuscrito objetiva apresentar a pesquisa-ação na APS como uma proposição metodológica facilitadora da análise das complexas tramas que envolvem o acesso à saúde na inter-relação com o desenvolvimento econômico e as implicações no trabalho e ambiente em comunidades no Nordeste brasileiro.

\section{Método}

\section{A pesquisa-ação como caminho para a investigação}

Este estudo se insere no campo das Ciências Sociais e da Saúde e, portanto, como referem Minayo, Deslandes e Gomes (2010, p.15), tem seu objeto essencialmente qualitativo, em que "a realidade social é a cena e o seio do dinamismo da vida individual e coletiva com toda a riqueza de significados dela transbordante". A pesquisa-ação foi usada na tessitura de uma dissertação de mestrado, como método para estudar o desenvolvimento econômico e as implicações no trabalho, ambiente e saúde em comunidades na APS no Nordeste brasileiro, com o intuito de elaborar, em parceria com o SUS local, um plano de ação em relação à saúde do trabalhador e saúde ambiental a ser implantado na ESF.

A escolha deste caminho metodológico relaciona-se ao fato de este aproximar-se da realidade social visando o conhecimento científico, sem desconsiderar os significados, crenças, simbologias dos envolvidos nos processos da vida cotidiana, que passa por transformações intrinsecamente ligadas ao modo de viver dos moradores e trabalhadores.

Concordamos com Bosi (2007) quando afirma que o objetivo deste tipo de pesquisa é compreender e/ou transformar a realidade. Contudo, sabemos que a escolha da metodologia de investigação jamais propiciará uma compreensão totalitária da realidade, pelas limitações e especificidades das diferentes abordagens metodológicas e da complexidade dos processos envolvendo a relação humana com o ambiente, o trabalho e a forma de se compreender saúde.

Minayo, Deslandes e Gomes (2010) assinalam a importância de trabalharmos com a complexidade, a especificidade e as diferenciações internas dos objetos que, segundo os autores, precisam ser contextualizados e tratados na sua singularidade. Corroborando esta ideia, consideramos que a pesquisaação favorece o desenvolvimento de um processo de interação entre pesquisadores e os sujeitos participantes da pesquisa. Acreditamos que ela apresenta, como potencialidade, aproximar os pesquisadores com os trabalhadores, profissionais do serviço de saúde e a comunidade, bem como o diálogo entre a ciência e a vida.

Destacamos que a pesquisa-ação é entendida, às vezes, como pesquisa participante. Por exemplo, para Haguette (2001), a pesquisa participante envolve um processo de: investigação, educação e ação, consistindo numa pesquisa educacional e orientada para ação. Segundo a autora, nesse tipo de 
PESQUISA-AÇÃO: PROPOSIÇÃO METODOLÓGICA ..

pesquisa, realizam-se, concomitantemente, a investigação e a ação, prezando-se pela construção conjunta de pesquisadores e participantes com vistas às mudanças e transformação social.

Ao lado disso, Thiollent (2008, p.17) faz uma distinção entre pesquisa participante e pesquisa-ação, explicando que

[...] toda pesquisa-ação é participativa, sendo a participação das pessoas implicadas nos problemas investigados absolutamente necessária, enquanto na pesquisa participante a participação é sobretudo participação dos pesquisadores e consiste em aparente identificação com os valores e os comportamentos que são necessários para sua aceitação pelo grupo considerado.

Dessa forma, para o autor, a pesquisa participante nem sempre seria uma pesquisa-ação, sendo esta última assim definida:

[...] a pesquisa-ação é um tipo de pesquisa social com base empírica que é concebida e realizada em estreita associação com uma ação ou com a resolução de um problema coletivo e no qual os pesquisadores e participantes representativos da situação ou do problema, estão envolvidos de modo cooperativo e colaborativo. (Thiollent, 2008, p.16)

Para fins metodológicos deste estudo, adotamos a compreensão explicitada por Thiollent (2008), tendo em vista que essas concepções estiveram presentes no decorrer da pesquisa.

A pesquisa-ação foi realizada no contexto da modernização agrícola na Chapada do Apodi-Ceará. Este cenário vivencia processos de reestruturação produtiva, centrado no agronegócio, inserindo o Ceará no mundo globalizado com severos impactos à saúde e ao ambiente (Rigotto, 2011). A referida Chapada é uma importante produtora de frutas para exportação, destacando-se a produção de melão de 78 mil toneladas (INSTITUTO BRASILEIRO DE GEOGRAFIA E ESTATÍSTICA - IBGE, 2012). Carneiro, Braga, Pessoa (2010) e Pessoa et al. (2011) referem que a percepção das comunidades quanto ao contexto de risco à saúde evidencia que o crescimento dos monocultivos acontece mediante o uso intensivo de agrotóxicos pela técnica de pulverização aérea, que acontece nas proximidades das comunidades e vilarejos, assinalando que a modernização agrícola tem transformado o modo de vida das comunidades.

A escolha deste método relacionou-se à sua sensibilidade para indagar, possibilitando a compreensão da complexidade da problemática da saúde, o papel da sociedade e do Estado, visando à ação transformadora das populações marginalizadas e excluídas. Para tal, constituímos um grupo de sujeitos, com os quais realizamos oficinas. Ressaltamos que a pesquisa foi desenvolvida conforme os parâmetros da Resolução no 196/96, do Conselho Nacional de Saúde, e aprovada pelo Comitê de Ética em Pesquisa (CEP) da Universidade Federal do Ceará.

Propusemos desenvolver, nesta pesquisa-ação, os seguintes passos:

1 Pesquisa documental: visando apropriar-se de informações relevantes e conhecer o perfil sóciohistórico, as condições sociodemográficas, socioeconômicas e epidemiológicas do município, em especial, no que se refere ao SUS local, aos problemas ambientais e aos processos produtivos. Utilizamos bases de dados secundários em sites oficiais, tais como: Instituto Brasileiro de Geografia e Estatística (IBGE), Portal do Governo do Estado do Ceará e da Secretaria de Saúde do Estado do Ceará (SESA); e Sistemas de Informação em Saúde tais como: Sistema de Informação de Mortalidade (SIM), Sistema Nacional de Agravos Notificáveis (SINAN), dentre outros.

\section{Visitas exploratórias:}

a) objetivando conversar com informantes-chave (usuários, profissionais da saúde e gestores do SUS) e realizar observação livre, registrando, em diário de campo, as percepções, a fim de obter mais informações sobre a realidade local, para identificar a equipe de saúde da família que comporia o grupo de pesquisa-ação; 
Para selecionarmos uma equipe de saúde da família que efetivamente atuasse num território com problemas relacionados à questão ambiental e do trabalho, indagávamos aos informantes-chave: qual a região do município que, na atualidade, mais enfrenta problemas socioambientais relacionados ao trabalho, que tem impactos na saúde da população? Além disso, elencamos alguns critérios que observávamos:

. Se o território vivenciava transformações advindas de processos produtivos, com mudanças na vida da comunidade que requeriam, de forma mais consistente, a intervenção/atuação da APS em relação à efetivação da saúde ambiental e do trabalhador;

. Interesse dos profissionais de saúde, dos movimentos sociais, dos usuários do SUS de efetivarem ações de saúde ambiental e do trabalhador;

. Necessidade da APS, de forma emergencial, de responder às necessidades de saúde da população e dos trabalhadores no contexto em transformações socioambientais e culturais;

. Incipiência da APS no acolhimento das necessidades de saúde relacionadas ao trabalho, por desconhecimento dos processos produtivos locais, e de que forma impactavam a saúde;

. Magnitude dos problemas socioambientais existentes no território.

b) Identificar como se estruturava a APS, a vigilância em saúde e o controle social;

c) Identificar os equipamentos e agentes sociais, conselho municipal de saúde (CMS) e de meio ambiente, sindicatos, associações de trabalhadores e cooperativas existentes, e convidá-los a participar da pesquisa;

d) Realizar reunião com a gestão municipal (secretário de saúde, coordenação da APS e da Vigilância em Saúde), equipes de saúde da família e CMS, para apresentação da pesquisa, e identificar a equipe que participaria do estudo, seguindo os critérios: equipe saúde da família de atuação rural-urbana com disponibilidade para integrar o grupo;

e) Realizar reunião para apresentação do projeto de pesquisa no território de atuação da equipe de saúde da família e definição dos sujeitos que participariam do grupo, mediante a assinatura do Termo de Consentimento Livre e Esclarecido (TCLE).

\section{Constituição do grupo}

A constituição do grupo ocorreu em uma reunião com duração de 4 horas, onde contextualizamos o problema e definimos: os objetivos, o método do processo de pesquisa, a relevância da questão para a comunidade e serviço de saúde, e solicitamos, entre os presentes, voluntários, que se dispusessem a participar das atividades grupais, durante 44 horas de encontros presenciais, com cronograma a ser elaborado coletivamente.

O grupo formado envolveu 14 sujeitos, denominado 'grupo de pesquisa'. Foi constituído por profissionais de saúde da APS, representados por uma equipe de saúde da família (médico, enfermeiro, agente comunitário de saúde, auxiliar de enfermagem e auxiliar de serviços gerais da unidade de saúde); representante da educação (uma professora da escola municipal); representante de usuários do SUS (duas pessoas reconhecidamente usuários do serviço local); representante dos trabalhadores (um trabalhador rural do agronegócio e o presidente da associação dos trabalhadores rurais); representante do conselho municipal de saúde (uma conselheira); representante do poder público (um vereador), e dois representantes dos movimentos sociais existentes na comunidade.

Após constituído o grupo, pactuamos o cronograma e os critérios de exclusão. Além disso, que o discurso elaborado no grupo seria entendido e analisado coletivamente, e não como sujeitos isolados. A agenda de encontros teve um intervalo médio de 21 dias, sendo que cada encontro do grupo correspondia a oito horas, totalizando uma carga horária de 44 horas, sendo denominados de oficinas. Quanto à exclusão do participante, foi definido não faltar três encontros do grupo. 


\section{Condução das oficinas grupais}

\section{Pressupostos teóricos}

Compreendemos que a motivação e o engajamento do grupo relacionam-se a fatores intrínsecos e extrínsecos. Com esse entendimento, consideramos que, no trabalho grupal, precisamos estar envolvidos e comprometidos uns com os outros, e atentos para a relevância das temáticas propostas na transformação do contexto social. Dessa forma, Libânio (2001, p.62) afirma que o grupo consiste no "[...] lugar de se aprender a ser e conviver a partir das experiências de vida".

Tomando como base as ideias do autor e acreditando que o processo desencadeado pela pesquisaação desafiaria a nossa capacidade de assumir e conduzir um processo de pesquisa efetivamente garantindo a participação engajada e promissora, propusemos atividades que fortalecessem a integração do grupo, tendo em vista o que nos ensina Ribeiro (1993, p.390) sobre grupo: "É um campo de força, onde cada um atua sobre o outro e onde um é a miniatura de todos, formando assim a matriz grupal, quando trabalhar um, seria trabalhar todos e trabalhar cada elemento individualmente".

Para a realização das oficinas, utilizamos os ensinamentos de Paulo Freire (1992, p.114), que nos aponta

[...] toda compreensão de algo corresponde cedo ou tarde, uma ação. Captado um desafio, compreendido, admitidas as hipóteses de resposta o homem age. A natureza da ação corresponde a natureza da compreensão. Se a compreensão é crítica ou preponderantemente crítica, ação também o será. Se é mágica a compreensão, mágica será a ação.

Considerando o que pensa Freire (1992) sobre o agir humano, utilizamos, como guia, os seus ensinamentos propostos na condução das oficinas. Evidencia-se que somente um método ativo, dialógico, participante, pode propiciar o debate das situações desafiadoras postas diante de um grupo, o que nos remeteu à problematização ou ação de problematizar. Nesta perspectiva, um estudo empírico realizado por Zanotto e De Rose (2003, p.48) interpreta o que o educador Paulo Freire propõe relativo à problematização.

O que está sendo enfatizado é o sujeito práxico: a ação de problematizar acontece a partir da realidade que cerca o sujeito; a busca de explicação e solução visa a transformar aquela realidade, pela ação do próprio sujeito (sua práxis). O sujeito, por sua vez, também se transforma na ação de problematizar e passa a detectar novos problemas na sua realidade e assim sucessivamente.

Desenvolvemos a pesquisa-ação considerando a compreensão Freireana e as sugestões de Thiollent (2008, p.75):

[...] quem são os atores ou unidade de intervenção? Como se relacionam os atores e as instituições: convergências, divergências, conflito aberto? Quais são os objetivos e metas tangíveis da ação e os critérios de avaliação? Como dar continuidade à ação, apesar das dificuldades? Como assegurar a participação da população e assegurar suas sugestões? Como controlar o conjunto do processo e avaliar os resultados?

A despeito desses autores, utilizamos, também, a perspectiva construcionista, entendendo tanto o sujeito como o objeto como construções sócio-históricas que precisam ser problematizadas e desfamiliarizadas, ou seja, implica problematizarmos a realidade (Spink, 1999). 


\section{Etapas operacionalizadas no desenvolvimento das oficinas}

Considerando os pressupostos teóricos apresentados, empregamos, para a condução das oficinas, três etapas:

A etapa a consistiu no ato de se submeterem os aspectos teórico-metodológicos elaborados pela pesquisadora à apreciação crítica dos sujeitos do grupo. Neste momento, o grupo teve a oportunidade de debater e refletir sobre a relevância do tema a ser abordado, ambiente - trabalho no território, as implicações para o processo de trabalho da APS e da comunidade. Além disso, consistiu num momento de reformulação dos objetivos e apropriação dos temas centrais para APS e comunidade em relação à saúde ambiental e do trabalhador, ou seja, a concepção conjunta do objeto de pesquisa.

A etapa $\boldsymbol{b}$ objetivou a elaboração de mediadores - mapas representativos da dinâmica social, ambiental e do trabalho no território, e a submissão destes à crítica dos sujeitos do grupo. Outrossim, o grupo foi subdividido em dois subgrupos que, inicialmente, refletiam sobre o tema proposto, e, em seguida, procediam à elaboração de um mapa contendo todos os elementos identificados como interferentes e essenciais para o entendimento dos problemas. Ainda, apresentavam suas elaborações para o outro subgrupo, que complementavam e criticavam.

Na etapa $c$ - problematização, solicitamos ao grupo que, partindo da análise dos elementos representados no mapa que caracterizavam o território, refletissem e expressassem suas reflexões acerca das seguintes indagações:

$\mathrm{Na}$ caracterização do lugar: Quais os marcos históricos vivenciados pela comunidade? Quem foram os primeiros habitantes a chegar? Quais os eventos mais importantes que aconteceram na comunidade? Que aspectos chamam atenção em relação à cultura, saúde, educação na comunidade? 0 que o grupo observa em relação ao trabalho e a economia na comunidade? Que importância tem a territorialização em saúde (elaboração de mapas) para o trabalho da Equipe Saúde da Família?

$\mathrm{Na}$ caracterização do trabalho: De que forma os processos produtivos têm relação com os problemas de saúde? Qual instituição (pública ou privada) é mais importante para o desenvolvimento da comunidade? Quais as organizações e grupos ativos na comunidade? Qual a percepção que o grupo tem sobre a atuação dessas instituições? Qual a interação que estas instituições têm entre si? Quais as estratégias de vida adotadas pelas pessoas da comunidade que não têm emprego? Quais os serviços existentes na comunidade? Quais os critérios para se ingressar nesses serviços? Quais os lugares fora da comunidade e a distância para onde as pessoas vão para obterem serviços? O que significa, para o grupo, o acesso a esses serviços? E ao trabalho? Quem são as pessoas que estão neste trabalho (sexo, procedência, idade, escolaridade)?

Na caracterização socioambiental e a relação com a saúde: De que forma se dá a relação trabalho-ambiente no território? Quais os riscos à saúde decorrentes do trabalho? Quais os problemas/ agravos à saúde decorrentes do trabalho? Quais os riscos à saúde relacionados ao ambiente? Quais os problemas/agravos à saúde relacionados ao ambiente? De que forma a equipe saúde da família pode intervir nesses riscos relacionados ao trabalho e ao ambiente? Qual o papel dos movimentos sociais, dos usuários do serviço de saúde, do poder público no enfrentamento dos problemas locais? De que forma percebem as políticas de saúde ambiental e saúde do trabalhador na Atenção Primária?

Deste processo de análise do território, nasceu o plano de ação que contempla ações a serem desenvolvidas de forma articulada e intersetorial, considerando as dimensões do trabalho e ambiente. As ações planejadas tiveram como base os problemas levantados pelo grupo e que foram considerados centrais à sua abordagem para dar respostas às questões relacionadas ao ambiente-trabalho na APS. A seguir, enumeramos as ações propostas:

I Realização de um Seminário sobre saúde ambiental e os efeitos causados pelos agrotóxicos;

II Criação de um grupo intersetorial com pessoas identificadas no Seminário;

III Criação do Conselho Local intersetorial (saúde, ambiente, cultura, esportes, educação, movimentos sociais, dentre outros);

IV Criação de Lei Municipal que regulamente a utilização dos bens naturais (desmatamentos, queimadas...); 
PESQUISA-AÇÃO: PROPOSIÇÃO METODOLÓGICA ..

V Realizar visitas e ações educativas nas escolas visando discutir/prevenir o uso de drogas entre os jovens:

VI Realizar levantamento/registro dos agravos à saúde relacionados ao trabalho que chegam à UBS;

VII Realizar visitas às empresas do agronegócio;

VIII Implantar, nas UBS do município, horário noturno semanal para atender os trabalhadores;

IX Identificar o fluxo de Atenção à Saúde do Trabalhador existente (município, micro, macrorregião) para encaminhamento adequado;

X Realizar seminários com os trabalhadores sobre uso dos Equipamentos de Proteção Individual (EPI);

XI Realizar visitas aos prostíbulos com intuito de desenvolver ação educativa, com as trabalhadoras do sexo, sobre os riscos à saúde, uso de preservativo e doenças.

\section{Desvelando a realidade por meio da pesquisa-ação: análise do material qualitativo}

Realizamos um estudo crítico e aprofundado dos discursos gravados e transcritos, considerando os elementos como a sintaxe, semântica, as metáforas, os níveis de percepção e envolvimento dos participantes. Em seguida, submetemos os conteúdos a uma categorização temática, reunindo-os em categorias de análise, organizadas com suporte em um diálogo aproximado com a literatura revisada para a pesquisa.

Utilizamos a Análise do Discurso (AD) para promovermos a análise das falas, pois acreditamos que esta consiste na mais adequada das tipologias de análise para o nosso objeto. Orlandi (2000) relata que o discurso pode ser entendido como o efeito de sentidos entre os locutores e a AD seria um estudo que visa extrair sentido dos textos, considerando que a linguagem não é transparente. Então, procura compreender a língua, fazendo sentido enquanto trabalho simbólico, parte do trabalho social geral, constitutivo do homem e da sua história (Orlandi, 2000). Dessa forma, a AD vai além da transmissão da informação, pois, para a mesma, não há linearidade na disposição dos elementos da comunicação, como se a mensagem resultasse de um processo. "O discurso tem sua singularidade, tem seu funcionamento que é possível apreender se não opomos o social e o histórico, o sistema e a realização, o subjetivo ao objetivo, o processo ao produto" (Orlandi, 2000, p.22).

Essa técnica atende o que nos propomos e nos possibilitou a inferência de conhecimentos relativos às condições de produção/recepção das mensagens, nos aproximando dos objetivos do estudo, seguindo os ensinamentos de Orlandi (2000, p.61): “ [...] o analista do discurso [...] não interpreta ele trabalha nos limites da interpretação, não se coloca fora da história, do simbólico ou da ideologia. Ele se coloca em uma posição deslocada que lhe permite contemplar o processo de produção dos sentidos em suas condições".

\section{Resultados e discussões}

Neste estudo de pesquisa-ação, os participantes apresentaram um perfil heterogêneo em relação à idade, escolaridade e ocupação. Quanto ao gênero, eram dez do sexo feminino e quatro masculinos, com idades variando de 18 a 52 anos. A escolaridade variava, desde participantes somente alfabetizados, outros com Ensino Fundamental incompleto, Ensino Médio, Ensino Superior até pósgraduação. Quanto às suas atividades laborais, declararam realizar: em casa, na igreja, na escola, na agricultura, no posto de saúde e na comunidade.

É importante destacar nesta sessão que, para fins deste artigo, apresentamos apenas o recorte que o grupo apresenta como elementos motivadores, que influenciaram e contribuíram para a participação nas oficinas, com destaque para: pontualidade, assiduidade, compromisso e dedicação no decorrer da pesquisa-ação.

Quanto à assiduidade nas oficinas grupais, os participantes apresentaram uma frequência média de $87 \%$, sendo que as faltas relacionaram-se a problemas de saúde e dificuldade de liberação no trabalho. $\mathrm{Na}$ oficina em que houve mais ausências, estas corresponderam a 21\%. No entanto, nenhum dos 
participantes faltou mais de duas oficinas e não houve nenhuma desistência. Isso demonstra a responsabilidade e o compromisso assumido com a pesquisa e, sobretudo, o compromisso coletivo, no decorrer do estudo. No último encontro pactuado, 85\% dos participantes referiram o desejo de continuarem com as oficinas grupais com o ajuste de realizarem atividades presenciais bimensais. Essa iniciativa nos impulsiona a inferir que as pessoas estão disponíveis para participarem ativamente, interagirem e proporem ações coletivas no enfrentamento das questões de saúde-ambiente-trabalho no território.

\section{A participação ativa como elemento motivador da pesquisa-ação}

Sabemos que a participação, o envolvimento dos sujeitos em processos participativos, que demandam disponibilidade de tempo e reorganização da vida das pessoas, consiste num desafio para estudos científicos, o que nos fez questionar por que estes sujeitos permaneceram de forma tão expressiva nesta pesquisa? Que aspectos podem ter sido desencadeados que colaboraram para o envolvimento dos sujeitos?

Acreditamos que a participação garantida, o respeito à diversidade de saberes, e, sobretudo, a valorização como sujeitos de direitos e corresponsáveis pelos processos de reflexão e tomada de decisão diante dos problemas vividos, fortaleceram o grupo. No discurso que segue, podemos perceber a identidade e o sentimento de pertença que contribuíram para o engajamento de todos:

“[...] estou gostando mais é da interação do grupo, conhecendo pessoas novas, é a participação! Todo mundo se empenhando para realizar esse trabalho, que vai ser em prol da comunidade como um todo. Então, as 15 pessoas que estão aqui estão trabalhando em prol dos dez mil habitantes daqui. São quinze pessoas que estão trabalhando para beneficiar a todos. Além do conhecimento, o que está sendo mais importante é essa disponibilidade das pessoas em estar tentando solucionar esse problema".

No relato, percebemos a integração entre os sujeitos pesquisados e pesquisador, quando refere 'das 15 pessoas trabalhando', neste caso, inclui a pesquisadora como membro do grupo. Ou seja, concebese uma igualdade e uma responsabilidade coletiva na busca de soluções para os problemas. Se expressa a não-neutralidade científica, que permeia, de forma concreta, a ação da ciência na promoção de uma visão ampliada sobre os processos instituídos nos territórios, aproximando a ciência da vida, sendo parte integrante e consequente da pesquisa-ação.

O grupo expõe a importância do conhecimento elaborado e partilhado, afirmando a necessidade de compartilhar esse entendimento com outros, demonstrando o movimento interno e o despertar do ser proativo:

“Foi de grande valia o que a gente pôde aprender e contribuir junto, e não só a questão do conhecimento, mas também estar com as pessoas, conhecer outras pessoas e compartilhar esse momento com todo mundo".

Os significados e sentidos são compreendidos numa perspectiva relacional, de reconhecimento do outro sujeito na história singular do lugar, e atentando para a relação que este sujeito estabelece com o meio social. A pesquisa-ação contribuiu na redescoberta da interação humana como fundamental para transpor diversos aspectos fragmentados, dicotomizados, desarticulados da compreensão da realidade, quando expressam 'foi uma apropriação mesmo do terreno' e ' foi um momento muito rico de construção junto com a comunidade':

“[...] no PSF tem aquela estória que você tem que está apropriado do seu terreno, então foi uma apropriação mesmo do terreno, de conhecer novas coisas que a gente não sabia. Porque a gente vai para comunidade, às vezes, a gente é tão atribulada de fazer, vou fazer pré-natal, vou fazer planejamento familiar, que você não pára para ver outras coisas que 
PESQUISA-AÇÃO: PROPOSIÇÃO METODOLÓGICA ..

estão ao seu redor, embora a gente saiba que a gente tem que ter análise da situação da nossa área, e também, a gente nunca tinha parado para fazer os mapas. Então, foi um momento muito rico de construção junto com a comunidade que a gente fez aqui durante esses dias".

Destacamos que, em nenhum momento, realizamos exposição oral ou leitura de textos sobre o lugar e os processos de transformação ocorridos no território. Apenas elaboramos perguntas que eram lançadas ao grupo. Então, os sujeitos aprendiam consigo mesmos, e ressignificavam a percepção do território, a partir de uma visão coletiva, na qual se integrava o saber técnico ao saber popular, como foi expresso 'gostei de estudar o lugar que a gente vive, que é como se fosse um estudo':

“[...] gostei da gente estudar o lugar que a gente vive, que é como se fosse um estudo. Estudar o lugar, a comunidade que você vive. Gostei de conhecer pessoas novas, pessoas tão interessantes. Acho que o mais importante foi essa relação que a gente teve de conhecer novas pessoas".

“[...] discutimos aqui muitas coisas importantes que precisam acontecer e que vai acontecer para que as pessoas se sintam melhores na área da educação, quanto da saúde e com certeza esse trabalho vai trazer muitos resultados para cá".

As pessoas envolvidas nesse processo relataram que se sentiram motivadas a se engajarem no grupo: pelo compromisso com a comunidade e seus problemas; contribuir com a pesquisa; e a oportunidade de colaborar para a melhoria da situação de saúde local.

"[...] a oportunidade de ajudar mais a minha comunidade".

“[...] interesse pela saúde da nossa gente, em especial a saúde dos trabalhadores e saúde ambiental".

"Contribuir para a pesquisa e [...] adquirir conhecimentos para melhorar as condições de vida desta população".

As pessoas demonstraram, em seus discursos, a preocupação com o processo em curso na comunidade e identificaram a necessidade de assumirem uma postura proativa de contribuição com a qualidade de vida da população. O grupo afirmou que suas expectativas na vivência dessa pesquisa-ação estavam relacionadas ao potencial de contribuição que tinham no desenvolvimento da pesquisa, desde a identificação de sinais e sintomas de agravos à saúde humana relacionados ao trabalho, até contribuírem para a mudança da atual situação de saúde, por meio da construção de conhecimentos e aplicabilidade prática do que fosse aprendido nos encontros.

Percebe-se um movimento, um desejo de sair da comodidade e trilhar novos caminhos objetivando ser parte; e, como parte, contribuir para melhorar a saúde dos trabalhadores e da população, bem como propiciar melhoria da qualidade de vida da comunidade.

“[...] melhorar a qualidade de vida das pessoas [...] ajudar o meio ambiente, a saúde [...] não moro aqui, mas a partir do momento que eu entro na comunidade eu me preocupo [...] com o bem-estar deles [...] é pensar em harmonia [...]".

Para alcançar suas expectativas, o grupo pontuou os aspectos em que poderiam contribuir com a construção de uma nova realidade, como podemos observar nas falas dos sujeitos:

"[...] contribuir com o que conheço sobre a minha comunidade. Participando das reuniões para aprender $[\ldots]^{\prime \prime}$. 
"Aconselhar as pessoas sobre este debate [...] orientar os trabalhadores e [...] a comunidade [...] colocando em prática o que for aprendido [...] para melhorar a qualidade de vida da população. Denunciando [...]".

\section{De indivíduos a grupo: uma elaboração a partir da pesquisa-ação}

O grupo, numa perspectiva colaborativa e cooperativa, constituiu-se por pessoas entusiasmadas, que demonstraram interesse em participar. Consideramos que a concretude da participação dos sujeitos relacionou-se ao processo de condução das oficinas, que se deu nas etapas: a) revisitar os objetivos e aspectos teórico-metodológicos; b) elaboração e apresentação dos mapas para apreciação crítica pelos sujeitos do grupo: c) problematização conduzida pela pesquisadora.

Em relação à etapa $a$, consideramos que o debate sobre os aspectos teórico-metodológicos foi fundamental para dar sentido à ação, ou seja, vivenciar de forma corresponsável. O pressuposto da participação ativa dos sujeitos embasou toda a pesquisa-ação, e a elaboração coletiva dos significados, percepções e compreensões. Favoreceu o desvelar dessas descobertas, dos sentidos, dos construtos que serviram ao grupo como estruturas de apoio. Portanto, acreditamos que, dentre as etapas da pesquisa-ação, o ato de revisitar os objetivos e os aspectos teórico-metodológicos e interrogá-los, propiciou a aproximação e a percepção dos vínculos existentes entre as proposições e o simbólico, o vivido, o sentido, o percebido no contexto, e foi de fundamental importância na / e para a participação dos sujeitos.

Em relação à etapa $\boldsymbol{b}$, ponderamos que o ato de expressar concretamente, no desenho do mapa, a percepção da realidade social, ambiental e do trabalho no território e submetê-la à análise crítica dos sujeitos do grupo, evidenciava os aspectos a serem complementados e reformulados. A análise crítica dos desenhos dos mapas de forma colaborativa e cooperativa, por todos que vivenciavam o processo, fortaleceu a igualdade e a identificação da complementaridade, e a interdependência de saberes necessária para se proceder a uma leitura complexa dos problemas do território.

A etapa $c$ propiciou a reinterpretação da vida no território favorecendo a elaboração da ideia e o debruçar-se sobre os problemas, as potencialidades, as interfaces da vida na comunidade e a formulação de novos sentidos. A formulação de perguntas indutoras da criticidade acerca da realidade dos sujeitos resultou na transformação dos indivíduos e o nascimento do envolvimento do grupo com a questão saúde-ambiente-trabalho, como visto no trecho que se segue:

"Estou dentro do grupo e quero fortalecer mais ainda e quero trazer mais colegas vereadores para discutir o que nós já discutimos aqui. [...] vou convidar o secretário de educação, o secretário de obras, de agricultura para que possa discutir e fortalecer para que a gente possa trazer bons resultados para cá, que é o pensamento do grupo. [...] Muito obrigado".

Essa pesquisa contribuiu, a partir de uma reflexão crítica durante o processo, para a mudança de atitude e a tomada de decisão. Além do respeito, valorização e reconhecimento do saber do grupo pelos sujeitos e pela pesquisadora, estas etapas possibilitavam a interação e o compartilhamento das ideias que fizeram com que a concepção do plano de ação em saúde ambiental e do trabalhador fosse uma necessidade coletiva, assumida sua implantação mesmo finda a pesquisa, conforme ressaltam:

“Eu vou continuar no grupo com certeza, me identifiquei muito com o grupo, apesar de ultimamente ter tido muitos afazeres na escola, mas, acho que minha vida, metade da minha vida é isso, fazendo parte desses projetos, dessas coisas para melhorar a minha comunidade, e sem dúvida nenhuma valeu a pena realmente a gente está aqui. Conhecimento a gente teve muito, muitas coisas que a gente não sabia que existia e, que agora já sabe, como o CEREST e outras coisas". 
PESQUISA-AÇÃO: PROPOSIÇÃO METODOLÓGICA ..

"A gente vai vendo mais aprofundado a realidade da nossa cidade, da nossa comunidade, e a partir daí a gente pode mudar as coisas, e quando tem pessoas competentes como todos que estão aqui, e, que, realmente quer mudar é mais fácil você levar adiante esse projeto".

\section{Considerações finais}

A partir deste ensaio, compreendemos que a pesquisa-ação constitui um aporte capaz de subsidiar o planejamento conjunto, a elaboração de proposições e ações num diálogo crítico e problematizador das fragilidades, necessidades, mecanismos de superação e adaptação às novas realidades que emergem no contexto de mudanças socioambientais no território local, espaço de atuação da APS. O caráter participativo e a ação podem semear mudanças no contexto local numa perspectiva emancipatória dos sujeitos.

Apreendemos que pesquisas socialmente engajadas promovem o fortalecimento e a participação da comunidade, de profissionais de saúde, gestores e trabalhadores, num movimento de produzir ciência na prática da vida comunitária, fortalecendo o modelo de atenção à saúde e, sobretudo, a APS.

Esse tipo de abordagem favorece a percepção ecossistêmica dos problemas de saúde e o avanço na proposição de políticas públicas de saúde que efetivem realmente o vínculo, o acolhimento das necessidades de saúde, a responsabilidade sanitária pelo território e a ação transdisciplinar e intersetorial.

O envolvimento dos sujeitos com os objetos de pesquisa dos pesquisadores, que são embasados nos problemas reais, apresenta-se como uma atuação científica necessária para a consolidação do SUS. Essa aproximação do acadêmico com o empírico, do teórico com o prático, em processos de pesquisa-ação, são potencialmente transformadores de indivíduos e coletivos. Esse processo está inter-relacionado com a promoção da afetividade e da criticidade, que são estruturais para a formação de novas práticas em saúde. Esse tipo de abordagem propicia aflorar o sentimento de pertença, e, portanto, de compromisso com a mudança, como descrito anteriormente em diversos trechos.

Evidencia-se que há um espaço promissor da criatividade, da autonomia e da inter-relação do sujeito que se constitui como objeto de estudo, quando estes não são compreendidos somente como fontes de informação, mas como sujeitos ativos, partícipes do conhecimento produzido, e capazes de apreender a transformar a realidade no curso da pesquisa. Ou seja, o processo de pesquisa em si já promove mudanças na singularidade de cada indivíduo que floresce no grupo. Então, as ações decorrentes da elaboração do plano de ação têm outra matriz de significados, porque são concebidas a partir da apropriação do universo práxico em que estão inseridos os sujeitos.

Nessa perspectiva, realizar pesquisa-ação em saúde ambiental e do trabalhador no SUS implicada com a práxis, garantindo um processo dialógico, embasado na problematização, fortalece a relação academia e serviço, contribuindo para a efetivação do direito à saúde, a participação social e a constituição de novas práticas de saúde na APS.

\section{Colaboradores}

Os autores trabalharam juntos em todas as etapas de produção do manuscrito. Vanira Matos Pessoa e Carlos André Moura Arruda realizaram a revisão final do manuscrito. 


\section{Referências}

BOSI, M.L.M.; MERCADO, F.J. Introdução: notas para um debate. In: qualitativa de serviços de saúde. 2.ed. Petropólis: Vozes, 2007. p.8-17.

BRASIL. Ministério da Saúde. Portaria n².488/GM, de 21 de outubro de 2011. Aprova a Política Nacional de Atenção Básica, estabelecendo a revisão de diretrizes e normas para a organização da atenção básica, para a Estratégia Saúde da Família (ESF) e o Programa de Agentes Comunitários de Saúde (PACS). Diário Oficial [da] República Federativa do Brasil, Brasília, DF, 24 out. 2011. Seção 1, n.204, p.48.

. Ministério da Saúde. Rede Interagencial de Informações para a Saúde. Indicadores e Dados Básicos - IDB 2009. 2012. Disponível em: <http:// tabnet.datasus.gov.br/cgi/idb2009/matriz.htm>. Acesso em: 18 jan. 2012.

Política Nacional de Atenção Básica. Brasília: Ministério da Saúde, 2006. (Série Pactos pela Saúde, v.4).

CARNEIRO, F.F.; BRAGA, L.Q.V.; PESSOA, V.M. Mapeamento de vulnerabilidades socioambientais e contextos de promoção da saúde ambiental em comunidades rurais do vale do Jaguaribe, Ceará. In: CONGRESSO LATINOAMERICANO DE SOCIOLOGIA RURAL, 8., 2010, Porto de Galinhas. Anais... Porto de Galinhas, 2010.

CEARÁ. Governo do Estado. Ceará em números. 2012. Disponível em: < http:// www.ceara.gov.br/portal_govce/ceara/ceara-em-numeros>. Acesso em: 12 jan. 2012.

DIAS, E.C. et al. Saúde ambiental e saúde do trabalhador na atenção primária à saúde, no SUS: oportunidade e desafios. Cienc. Saude Colet., v.14, n.6, p.2061-70, 2009.

FREIRE, P. Educação e conscientização. In: 21.ed. São Paulo: Paz e Terra, 1992. p.21-7.

Educação como prática da liberdade.

HAGUETTE, T.M.F. Metodologias qualitativas na sociologia. Petropólis: Vozes, 2001.

INSTITUTO BRASILEIRO DE GEOGRAFIA E ESTATÍSTICA - IBGE. Estatísticas. 2012.

Disponível em: <http://www.ibge.gov.br/home/estatistica/populacao/ estimativa2009/POP_2009_TCU.pdf>. Acesso em: 9 ago. 2012.

LIBÂNIO, J.B. A arte de formar-se. 2.ed. São Paulo: Edições Loyola, 2001.

MINAYO, M.C.S.; DESLANDES, S.F.; GOMES, R. Pesquisa social: teoria, método e criatividade. 29.ed. Petropólis: Vozes, 2010.

ORLANDI, E.P. Análise do discurso: princípios e procedimentos. Campinas: Pontes, 2000.

PESSOA, V.M. Abordagem do território na constituição da integralidade em saúde ambiental e do trabalhador na atenção primária à saúde em Quixeré-Ceará. 2010. Dissertação (Mestrado) - Programa de Pós-Graduação em Saúde Coletiva, Universidade Federal do Ceará, Fortaleza. 2010.

PESSOA, V.M. et al. As novas necessidades de saúde nos territórios dos sertanejos do baixo Jaguaribe-CE e os desafios à política pública de saúde. In: RIGOTTO, R.M. (Org.). Agrotóxicos, trabalho e saúde: vulnerabilidade e resistência no contexto da modernização agrícola no baixo Jaguaribe/CE. Fortaleza: Edições UFC, 2011. p.549-83.

RIBEIRO, J.P. Gestalt - terapia: o processo grupal. São Paulo: Summus Editorial, 1993.

RIGOTTO, R.M. (Org.). Agrotóxicos, trabalho e saúde: vulnerabilidade e resistência no contexto da modernização agrícola no baixo Jaguaribe/CE. Fortaleza: Edições UFC, 2011.

RIGOTTO, R.M.; AUGUSTO, L.G.S. Saúde e ambiente no Brasil: desenvolvimento, território e iniquidade social. Cad. Saude Publica, v.23, supl.4, p.S475-85, 2007. 
PESQUISA-AÇÃO: PROPOSIÇÃO METODOLÓGICA .

SANTOS, T.C.C.; CÂMARA, J.B.D. GEO Brasil 2002: perspectivas do Meio Ambiente no Brasil. Brasília: Edições Ibama, 2002.

SPINK, M.J. (Org.). Práticas discursivas e produção de sentidos no cotidiano: aproximações teóricas e metodológicas. São Paulo: Cortez, 1999.

THIOLLENT, M. Metodologia da pesquisa-ação. 16.ed. São Paulo: Cortez, 2008.

ZANOTTO, M.A.C.; DE ROSE, T.M.S. Problematizar a própria realidade: análise de uma experiência de formação contínua. Educ. Pesqu., v.29, n.1, p.45-54, 2003.

PESSOA, V. M. et al. Investigación-acción: propuesta metodológica para la planificación de las acciones en los servicios de atención primaria en el contexto de la salud ambiental y ocupacional. Interface (Botucatu), v.17, n.45, p.301-14, abr./jun. 2013.

El sistema gubernamental de salud brasileño (SUS) propone la realización de acciones para la salud del medio ambiente y de los trabajadores, con la finalidad de abordar la complejidad del proceso salud-enfermedad en los territorios. El objetivo es presentar la investigación-acción como una jornada metodológica, facilitadora del análisis de las complejas redes de desarrollo económico y las implicaciones para el trabajo, el medio ambiente y la salud en las comunidades de la región nordeste de Brasil. La investigación-acción fue diseñada con un grupo de 14 personas y realizada bajo la forma de talleres. Durante la investigación surgieron vínculos y preparación de propuestas, originadas de la teorización-reflexión-acción de los sujetos. Se subraya que el método tiene potencial para plantear los problemas relacionados con la salud ambiental y del trabajador, ya que favorece la interacción humana integrada al lugar en que vive.

Palabras clave: Investigación-acción. Salud ambiental. Salud laboral. Atención primaria de salud.

Recebido em 18/05/12. Aprovado em 08/02/13 